\title{
Influência da cinza pesada empregada em substituição ao agregado natural nos mecanismos de transferência de umidade em argamassas
}

\author{
SANTOS, F. I. G., ROCHA, J. C., CHERIAF, M. \\ Universidade Federal de Santa Catarina - UFSC - Departamento de Engenharia Civil Núcleo de Pesquisa em \\ Construção - Laboratório ValoRes Valorização Resíduos e Materiais Campus Trindade \\ 88040-900 Florianópolis SC \\ e-mail: flora_engcivil@yahoo.com.br, ecv1jcr@ecv.ufsc.br, malik@infohab.org.br
}

\begin{abstract}
RESUMO
O estudo da transferência de umidade é importante para a caracterização do comportamento das argamassas notoriamente no que se refere à durabilidade, à estanqueidade, à degradação de aspecto e ao desempenho térmico. No entanto, as pesquisas que abordam propriedades relacionados aos mecanismos de transferência de umidade apresentam resultados válidos apenas para argamassas convencionais. Em contrapartida, o uso de resíduos sólidos industriais e o emprego de aditivos têm sido cada vez mais intenso na construção civil. O objetivo do presente trabalho foi realizar a avaliação das propriedades relacionadas com os mecanismos de transferência de umidade não somente de argamassas convencionais, mas também de argamassas confeccionadas com teores de 50 e $100 \%$, em volume, de cinzas pesadas em substituição ao agregado natural, contendo ou não aditivo incorporador de ar. A escolha da cinza pesada advém da grande disponibilidade deste resíduo na região sul do Brasil e da sua característica peculiar de apresentar conteúdo de umidade de equilíbrio bastante superior ao da areia. O estudo também abordou o aditivo incorporador de ar, pelo fato de atuar na formação de alvéolos não interligados ao longo dos capilares e promover a redução na massa específica aparente. As propriedades avaliadas foram: massa específica, porosidade aberta, cinética de absorção de água por capilaridade, cinética de secagem, adsorção e ângulo de molhamento aparente. Os resultados mostraram que o teor de cinza pesada e o emprego de aditivo incorporador de ar são parâmetros que afetam significativamente as propriedades relacionadas com a transferência de umidade. O programa experimental permitiu evidenciar que a natureza da cinza determina o nível da fixação de umidade da argamassa e a sua dinâmica na fixação.
\end{abstract}

Palavras chaves: argamassas, cinzas pesadas, durabilidade, transferência de umidade, incorporador de ar.

\section{Influence of bottom ash replaced natural aggregate and air-entraining agent in moisture transfer mechanisms in mortars}

\begin{abstract}
The study of moisture transfer has great importance for the characterization of mortars behavior, particularly in relation to durability, waterproofing, aesthetics degradation and the thermal performance. However, researches on properties related to moisture transfer mechanisms present applicable results only for conventional mortars. On the other hand, the use of industrial solid residues and admixtures are increasing in civil construction activities. The present work evaluated the properties related to moisture transfer mechanisms not only in conventional mortars, but also in mortars with 50\% and $100 \%$ natural aggregate replaced by bottom ash, by volume, and with and without air-entraining agent. Bottom ash was chosen because it is a residue of great availability in southern Brazil, and its equilibrium moisture content is higher than that of sand, reflecting its porous nature. In relation to admixtures to cement-based materials, airentraining agent deserves prominence because it increases the disconnection of the capillary network and decreases the specific gravity. The evaluated properties had been: specific gravity, porosity, water absorption by capillarity, air drying, water vapor sorption isotherms and apparent wetting angle. The results show that the bottom ash percentage and the air-entraining agent are parameters that significantly affect the properties related with the moisture transfer.
\end{abstract}

Keywords: mortar, bottom ash, durability, moisture transfer, air-entraining agent. 


\section{INTRODUÇÃO}

As transferências de umidade ocorrem durante a vida inteira dos materiais. Notadamente para aqueles materiais à base de cimento Portland, onde a água está presente desde os primeiros momentos da produção. Em seguida, durante a hidratação, uma parte desta água desparece para formar o gel enquanto que a água em excesso se evapora deixando uma rede de poros chamados poros capilares. Esta rede de poros é o local privilegiado do transporte de água sob forma de vapor ou líquida. Além do mais, durante a sua vida útil, o transporte e fixação de umidade ocorrem com o processo de secagem do material, se submetido a um ambiente com umidade relativa mais baixa do que sua umidade interna. Esse fenômeno afeta a zona de superfície de muitas estruturas de engenharia. Além disso, esses processos são combinados freqüentemente com outros processos maciços de transporte ou com as reações químicas que ocorrem em condições não saturadas, tais como a carbonatação ou a penetração de agentes agressivos [1]. Tais fatos indicam a necessidade de compreender perfeitamente e poder simular as transferências de umidade

Diversos autores vêem conduzindo pesquisas direcionadas à avaliação dos mecanismos de transferência em materiais porosos [2-7]. Além da importância da avaliação dos materiais a análise dos mecanismos tornam-se ferramentas de apoio para análise de comportamento térmico das edificações assim como para as indústrias da cadeia produtiva de materiais de construção. Vários trabalhos buscam também correlacionar as propriedades de transporte com a estrutura dos materiais à base de cimento Portland [ㅁ-11]

$\mathrm{O}$ uso de cinzas pesadas em substituição a areia natural tem mostrado grande potencial de aproveitamento para produção de materiais à base de cimento Portland [11] e [12]. Além da problemática ambiental, a relevância do estudo com as cinzas da queima de carvão mineral deve-se ao fato do conteúdo de umidade de equilíbrio destas ser bastante superior ao da areia em razão da sua natureza porosa [12]. O desenvolvimento de materiais com as cinzas pesadas necessita de uma inventigação da natureza das cinzas e o seu efeito no comportamento hídrico do material polifásico desenvolvido.

Procurou-se no presente artigo avaliar o efeito das cinzas quanto transferência de umidade de argamassa de revestimento. Foram avaliadas as propriedades relacionadas com os mecanismos de transferência de umidade em argamassas de cimento e cal com três teores diferentes de substituição $(0,50$ e $100 \%$ ), em volume, de areia por cinza pesada. Para cada um destes teores foram confeccionadas argamassas contendo ou não aditivo incorporador de ar.

\section{MECANISMOS DE TRANSFERÊNCIA DE UMIDADE}

Os mecanismos que regem a transferência de umidade em materiais de construção são complexos e atuam simultaneamente [8]:

- na fase vapor, a difusão e os movimentos convectivos no interior dos poros condicionam o transporte;

- na fase líquida, a capilaridade, a gravidade e o efeito dos gradientes de pressão externa comandam a transferência de umidade.

Do ponto de vista físico pode-se considerar que há três mecanismos fundamentais de fixação de umidade: adsorção, condensação e capilaridade.

A partir da compreensão desses mecanismos que regem a transferência de umidade, modelos teóricos de transferência conjunta de calor e umidade foram desenvolvidos com base na mecânica dos fluidos utilizando as leis de difusão de massa (fase líquida - Lei de Darcy e fase vapor - Lei de Fick) e de difusão de calor (Lei de Fourier). Dentre esses modelos destacam-se o Modelo de Glaser (1959), o Modelo de KrischerVos (1969) e o Modelo de Philip- De Vries (1957). Tais modelos macroscópicos e fenomenológicos são uma generalização da Lei de Darcy (para um escoamento líquido) e uma extensão aos meios porosos da Lei de Fick (para uma difusão gasosa). Para entender a transferência de umidade através de uma argamassa microporosa constituída com as cinzas pesadas é proposta uma avaliação em três etapas:

1. análise microscópica para descrever a transferência e fixação da umidade através de um poro elementar suposto cilíndrico;

2. determinação das isotermas de adsorção, em que a superfície dos poros supostos cilíndricos é descrita a partir de um modelo BET;

3. estimativa de coficientes efetivos do material que poderão ser integrados nos modelos macroscópicos de comportamento.

A seguir, são fornecidos os diferentes fenômenos físicos que descrevem as interações entre a água e um meio poroso. 


\subsection{Adsorção}

Adsorção é a forma pela qual um material poroso varia o seu conteúdo de umidade em função da variação da umidade relativa. Os materiais que apresentam esse comportamento são denominados de higroscópicos. Nessa denominação está envolvida a maior parte dos materiais de construção civil.

Quando há um aumento do conteúdo de umidade do material trata-se do fenômeno de adsorção, quando ocorre a diminuição trata-se do fenômeno de dessorção. Ambos os fenômenos consistem no processo de ligação ou retenção de moléculas na superfície de partículas sólidas regido pelas forças de Van der Walls.

Modelos como o de Langmuir, o de BET (Brauner, Emmette Teller) e o de GAB (Guggenheim, Anderson, De Boer) foram propostos para o ajuste dos dados experimentais de adsorção e dessorção. Estes modelos estão detalhadamente descritos em [4] e segundo este autor o modelo de GAB é o que melhor ajusta-se aos dados experimentais para o caso das argamassas.

Através do emprego do modelo GAB é possível determinar a superfície específica (Se) do material por meio da Equação (1):

$$
S e=\frac{N_{A V G} \times W_{m} \times \rho_{s} \times A_{m}}{V_{m}}
$$

onde:

$\mathrm{N}_{\mathrm{AVG}}$ é o número de avogrado;

$\mathrm{W}_{\mathrm{m}}$ é o conteúdo mássico correspondente à formação de uma camada de moléculas recobrindo toda a superfície sólida determinado através do modelo GAB;

$\rho_{\mathrm{s}}$ é a massa específica aparente do material seco;

$\mathrm{V}_{\mathrm{m}}$ é o volume molar do adsorvato (água);

$\mathrm{A}_{\mathrm{m}}$ é a área de recobrimento de uma molécula adsorvida.

O conteúdo mássico de umidade "W" é definido como a relação entre o conteúdo de umidade e a massa da amostra seca.

\subsection{Condensação}

A argamassa, devido à sua estrutura porosa, quando exposta às condições climáticas, é capaz de fixar e transferir umidade tanto na fase líquida como na fase vapor. A umidade na forma de vapor é fixada nos poros da argamassa através dos processos de adsorção física e condensação capilar. Em condições isotérmicas, a água fixada é transportada para o interior do material através de mecanismos que dependem das dimensões do poro e da umidade relativa.

Existem dois modos de condensação da água, que são: água adsorvida e água capilar.

A água adsorvida é composta por camadas de moléculas que condensam sobre a superfície dos poros. Sua quantidade no equilíbrio é função da superfície específica do meio poroso, da afinidade entre o vapor de água e a matriz sólida e as condições higrotérmicas reinantes.

A água capilar representa uma fase contínua de líquido que preenche totalmente certos poros do material. Existe, nesse caso, uma descontinuidade de pressão na interface da curva que separa a água capilar da fase sólida.

De acordo com a lei de Kelvin-Laplace, a condensação capilar ocorre nos poros de raios menores que o raio crítico, cujo valor é calculado pela Equação (2):

$$
r_{c} \geq-\frac{2 \times M \times \sigma \times \cos \alpha}{\rho_{l} \times R \times T \times \ln (U R)}
$$

onde:

$\mathrm{r}_{\mathrm{c}}$ é o raio crítico;

M é a massa molecular da água;

$\sigma$ é a tensão superficial da água;

$\alpha$ é o ângulo de contacto entre a água e a superfície do poro;

$\rho_{\mathrm{l}}$ é a densidade da água;

$\mathrm{R}$ é a constante universal dos gases;

$\mathrm{T}$ é a temperatura;

UR é a umidade relativa $(0<\mathrm{UR}<1)$. 


\subsection{Capilaridade}

A capilaridade é a propriedade dos materiais porosos de absorverem e transportarem água através de sua rede de capilar.

O fenômeno da capilaridade gera interfaces curvas entre o fluído (água) e o ar contido no interior dos poros. Na interface líquido-gás estabelece-se um gradiente de pressões designado por pressão capilar que é função da tensão superficial líquido-ar $(\sigma)$, dos raios de curvatura principal $\left(\mathrm{R}_{\mathrm{x}}\right)$ e do ângulo de molhamento $(\alpha)$ conforme apresentado pela Equação (3):

$$
P_{c}=P_{a r}-P_{\text {agua }}=\sigma \times \cos \alpha \times\left(\frac{1}{R_{1}}+\frac{1}{R_{2}}\right)
$$

A influência da força gravitacional nas taxas de umidade transportada é pequena para a grande maioria dos materiais de construção nas suas condições usuais de aplicação [9].

Como visto na equação anterior o fenômeno de capilaridade depende do ângulo de molhamento, sendo que este é formado na interface entre o menisco capilar (esférico) e parede do poro, conforme ilustrado na Figura 1.

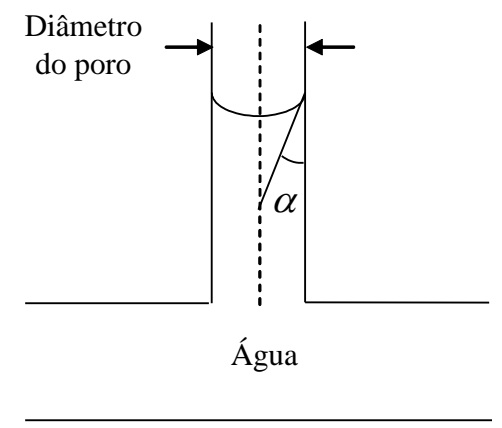

Figura 1: Esquema do ângulo de molhamento

A determinação deste ângulo baseia-se em um procedimento experimental geralmente aplicado em solos, que propõe a determinação do ângulo de molhamento aparente $(\alpha)$ por meio da avaliação da ascensão capilar em ensaio realizado em argamassas considerando-se a cinética de absorção capilar de dois líquidos molhantes diferentes: água e álcool [4]. O uso do álcool explica-se pelo fato deste ser considerado um líquido perfeitamente molhante, ou seja, o ângulo de molhamento é praticamente nulo em função do menisco capilar ser plano. Logo, a absorção capilar de álcool implica uma diferença de pressão praticamente nula que acarreta uma pequena força capilar. Dessa forma o ângulo de molhamento pode ser calculado pela equação (4):

$$
\cos \alpha=\left(\frac{V_{a}}{V_{a l}}\right)^{2} \frac{\mu_{a} \times \sigma_{a l}}{\mu_{a l} \times \sigma}
$$

onde:

$\alpha$ é o ângulo de molhamento aparente;

$\mu_{\mathrm{a}}$ é a viscosidade dinâmica da água;

$\mu_{\mathrm{al}}$ é a viscosidade dinâmica do álcool;

$\sigma$ é a tensão superficial água-ar;

$\sigma_{\mathrm{al}}$ é a tensão superficial álcool-ar;

$\mathrm{V}_{\mathrm{a}}$ é a inclinação da reta que relaciona o estoque de água infiltrado $\mathbf{V f}(\sqrt{ } \mathbf{t})$ com a raiz do tempo;

$\mathrm{V}_{\mathrm{al}}$ é a inclinação da reta que relaciona o estoque de álcool infiltrado $\mathbf{V f}(\sqrt{\mathbf{t}})$ com a raiz do tempo.

O estoque de líquido infiltrado, $\mathbf{V} \mathbf{f}(\sqrt{ } \mathbf{t})$ pode ser obtido pela aplicação da Equação (5):

$$
V_{t}(t)=\frac{m(t)-m s}{\rho_{l} \times A}
$$


onde:

$\mathrm{m}(\mathrm{t})$ é a massa do corpo de prova num determinado instante;

ms é a massa do corpo de prova;

$\rho_{1}$ é a massa específica do líquido molhante;

A é área da seção transversal do corpo de prova.

Através do ensaio de absorção por capilaridade também é possível determinar um coeficiente denominado de sorptividade (s) que está descrito na Equação (6):

$$
X=s \times \sqrt{t}
$$

onde:

$\mathrm{X}$ é o volume do líquido absorvido por área da seção transversal do corpo-de-prova;

t é o tempo.

A definição conceptual deste coeficiente está apresentada na Equação (7):

$$
s=\sqrt{\frac{\sigma \times r_{c}}{2 \times \mu}}
$$

onde:

$\sigma$ é a tensão superficial da água;

$\mu$ é o coeficiente de viscosidade dinâmica;

$\mathrm{r}_{\mathrm{c}}$ é o raio característico do poro.

\section{MATERIAIS E MÉTODOS}

\subsection{Materiais Utilizados}

Os materiais empregados na presente pesquisa foram: cimento Portland composto com adição de filler calcário, $\mathrm{CP}-\mathrm{II}-\mathrm{F}$, classe 32; cal hidratada do tipo $\mathrm{CH}-\mathrm{III}$, areia natural e cinza pesada; aditivo incorporador de ar (IA) em pó de base ligno-sulfonado e água.

As cinzas pesadas são materiais sílico-aluminosos. Além da sua composição química, apresenta como uma das vantagens para uso em substituição à areia natural a sua massa específica baixa $\left(1,80 \mathrm{~g} / \mathrm{cm}^{3}\right)$ em relação à massa específica da areia $2,57 \mathrm{~g} / \mathrm{cm}^{3}$. Na Tabela 1 , estão apresentadas as principais características físicas dos agregados (areia e cinza pesada CZP).

Tabela 1: Características físicas dos agregados

\begin{tabular}{|l|c|c|}
\hline \multicolumn{1}{|c|}{ Características } & Areia & Cinza Pesada CZP \\
\hline Módulo de finura & 2,02 & 1,22 \\
\hline D50 $0^{(1)}(\mathrm{mm})$ & 0,48 & 0,23 \\
\hline Massa unitária $\left(\mathrm{kg} / \mathrm{m}^{3}\right)$ & 1410 & 610 \\
\hline Massa específica $\left(\mathrm{kg} / \mathrm{m}^{3}\right)$ & 2570 & 1800 \\
\hline Material Pulverulento $(\%)$ & 4,08 & 9,81 \\
\hline Perda de massa ao fogo $(\%)$ & 1,15 & 4,44 \\
\hline
\end{tabular}

Nota: (1) D50 é o diâmetro médio do agregado, determinado através da abertura da peneira correspondente a $50 \%$ da fração mássica retida acumulada no peneiramento a seco.

A cinza pesada é composta principalmente por óxidos de silício, alumínio, potássio e ferro, e pertence à classe F, segundo a classificação proposta pela ASTM C618 [13]. A pozolanicidade das cinza 
pesadas foi evidenciada pela análise do consumo de hidróxido de cálcio por Cheriaf et al [11]. Na análise da pozolanicidade estabelecida por norma, o índice obtido foi de 0,73, conforme o procedimento NBR5752 [14]. Na Tabela 2, encontram-se apresentadas a composição química da CZP obtida por espectrometria por energia dispersiva, EDX 700 da Shimadzu, e análise do cimento fornecida pelo fabricante. Para a análise química, a amostra foi reduzida para uma dimensão inferior a $150 \mu \mathrm{m}$, com a prensagem de uma alíquota representativa da amostra.

Tabela 2: Composição química da cinza pesada e do cimento Portland

\begin{tabular}{l|l|l|l|l|l|l|l}
\hline \multicolumn{1}{l}{ Cinza Pesada } & \multicolumn{5}{l}{ Cimento Portland CP II_F 32* } \\
\hline Óxidos & $(\%)$ & Óxidos & $(\%)$ & Óxidos & $(\%)$ & Óxidos & $(\%)$ \\
\hline $\mathrm{SiO}_{2}$ & 41,789 & $\mathrm{SnO}_{2}$ & 0,046 & $\mathrm{SiO}_{2}$ & 18,28 & $\mathrm{SnO}_{2}$ & ---- \\
$\mathrm{Al}_{2} \mathrm{O}_{3}$ & 38,209 & $\mathrm{~V}_{2} \mathrm{O}_{5}$ & 0,031 & $\mathrm{Al}_{2} \mathrm{O}_{3}$ & 4,20 & $\mathrm{~V}_{2} \mathrm{O}_{5}$ & ---- \\
$\mathrm{K}_{2} \mathrm{O}$ & 9,043 & $\mathrm{SO}_{3}$ & 0,029 & $\mathrm{~K}_{2} \mathrm{O}$ & --- & $\mathrm{SO}_{3}$ & 2,87 \\
$\mathrm{Fe}_{2} \mathrm{O}_{3}$ & 4,366 & $\mathrm{MnO}$ & 0,026 & $\mathrm{Fe}_{2} \mathrm{O}_{3}$ & 2,38 & Resíduo & \\
$\mathrm{TiO}_{2}$ & 0,810 & $\mathrm{ZnO}$ & 0,014 & $\mathrm{TiO}_{2}$ & 0,810 & Insolúvel & 1,24 \\
$\mathrm{CaO}$ & 0,698 & $\mathrm{Y}_{2} \mathrm{O}_{3}$ & 0,013 & $\mathrm{CaO}$ & 60,46 & Equação & \\
$\mathrm{MgO}$ & 0,402 & $\mathrm{SrO}$ & 0,013 & $\mathrm{MgO}$ & 4,94 & Alcalina & 0,58 \\
$\mathrm{ZrO}_{2}$ & 0,071 & $\mathrm{CO}_{2}$ & 4,440 & $\mathrm{CaOlivre}$ & 1,52 & $\mathrm{CO}_{2}$ & 5,01 \\
\hline
\end{tabular}

* Nota 2: Análise do fabricante.

No difratograma da cinza pesada, é possível identificar as seguintes fases cristalinas majoritárias: quartzo $\left(\mathrm{SiO}_{2}\right)$ e mulita $\left(3 \mathrm{Al}_{2} \mathrm{O}_{3} \cdot 2 \mathrm{SiO}_{2}\right)$, e uma fase minoritária: a hematita $\left(\mathrm{Fe}_{2} \mathrm{O}_{3}\right)$ associada ao teor de óxido de ferro presente na cinza, Figura 2. A análise mineralógica foi realizada no aparelho Rigaku com radiação $\mathrm{CuKa}$ de $\lambda=1,5456 \AA$, tensão de $30 \mathrm{kV}$ e corrente elétrica de $15 \mathrm{~mA}$; sendo a varredura feita em $2 \theta$ de 10 à $65^{\circ}$, razão de $1 \%$ min e passo de $0,05^{\circ}$. Para a identificação das fases presentes na cinza e de dados estruturais destas fases (parâmetros de célula, posições atômicas e grupo espacial) utilizou-se o "Inorganic Crystal Structure Database" (ICSD).

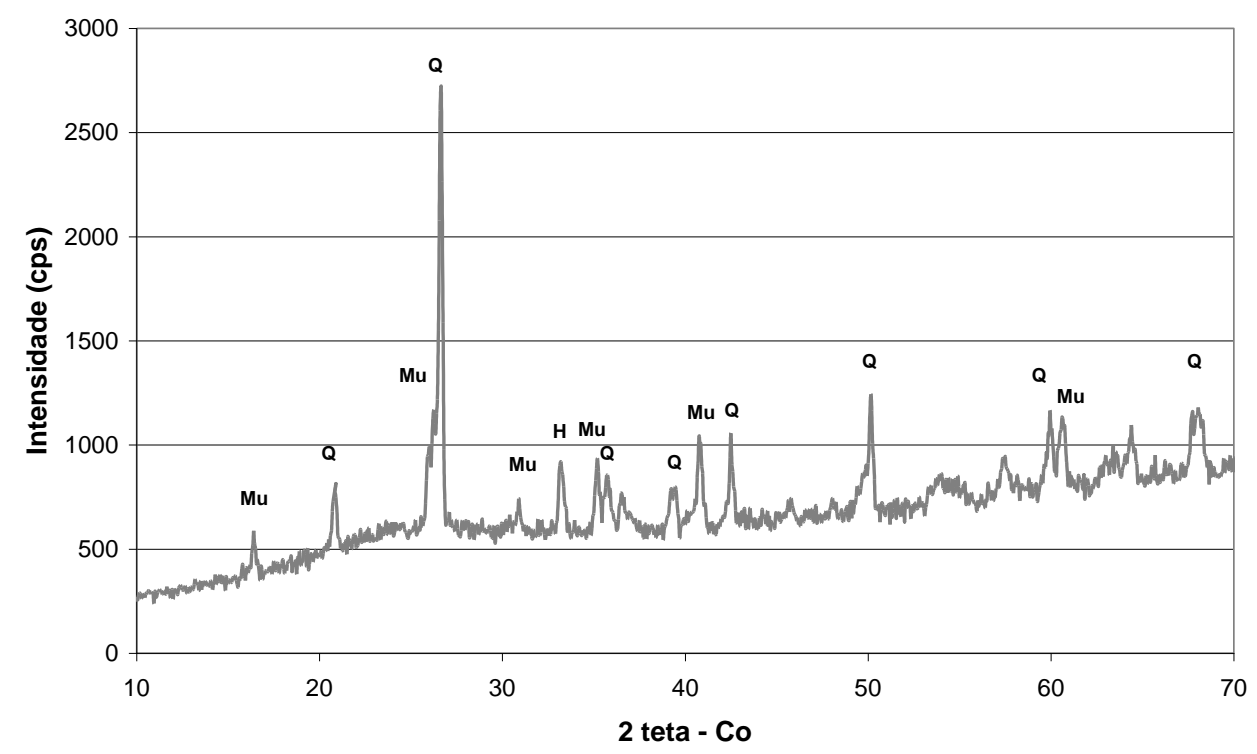

Figura 2: Difratograma da cinza pesada.

Q: quartzo (SiO2); M: mulita (3Al2O3.2SiO2); H: hematita (Fe2O3). 
Devido ao processo de queima as cinzas apresentam formas esféricas ou aglomerações de esferas com microporosidade. Na Figura 3, encontra-se a micrografia eletrônica realizada na fração média das cinzas pesadas .

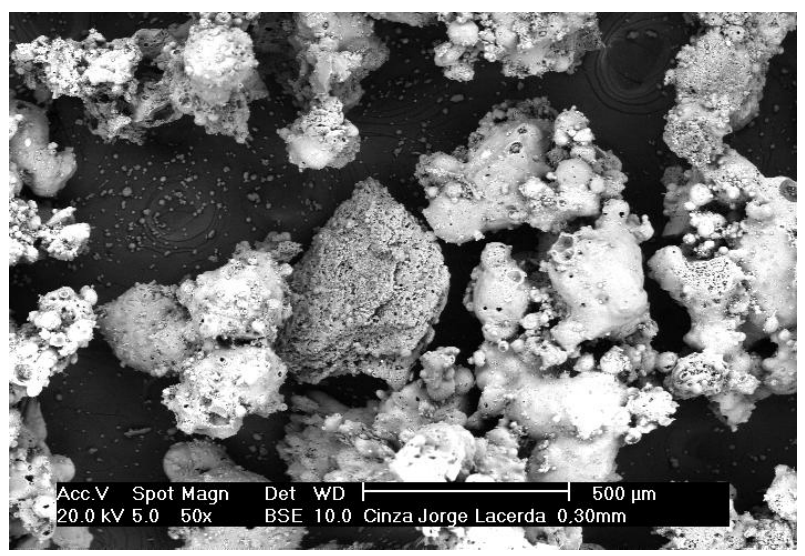

Figura 3: Micrografia das cinzas pesadas (fração média). Aumento de 50 vezes.

\subsection{Programa Experimental}

Foram produzidas argamassas a partir de uma formulação (traço base) em volume composta de $10,91 \%$ de cimento, $30,64 \%$ de cal e $58,45 \%$ de areia. A formulação de base foi realizada com o melhor proporcionamento entre os materiais que assegurasse uma argamassa sem pulverulência e sem fissuras quando aplicada em uma placa de vidro e submetida a secagem em estufa ventilada a $50^{\circ} \mathrm{C}$ durante $6 \mathrm{~h}$. A partir da formulação base foram produzidas argamassas com a substituição em volume de areia por cinza pesada nos teores de 0, 50 e $100 \%$, onde as cinzas foram incorporadas secas, através secagem em estufa ventilada na temperatura $105^{\circ} \mathrm{C}$ durante $24 \mathrm{~h}$. Para cada um dos teores de substituição da areia pela cinza pesada foram confeccionadas argamassas com e sem o uso de aditivo incorporador de ar. Em razão da natureza das cinzas pesadas, a relação água/cimento ( a/c) foi de 2,29 para todas as argamassas. A demanda elevada de água deve-se à estrutura das cinzas e ao fato dessas terem sido empregadas em misturas anidras. Logo, a composição de referência $(0 \% \mathrm{CZP})$, tem pouca similariedade com as argamassas usuais devido ao elevado volume de água empregado. Na série de argamassa com uso de aditivos, a quantidade de aditivo empregado foi de de $0,03 \%$ em relação à massa total de material seco.

A nomenclatura utilizada para as argamassas estudadas, bem como as formulações destas encontram-se sintetizadas na Tabela 3.

Tabela 3: Nomenclatura e formulação das argamassas (\% em volume)

\begin{tabular}{l|c|c|c|c|c}
\hline & & & & $\begin{array}{c}\text { Cinza } \\
\text { Pesada } \\
\text { CZP }\end{array}$ & $\begin{array}{c}\text { Aditivo } \\
\text { IA }\end{array}$ \\
\hline $0 \%$ CZP & 10,91 & 30,64 & 58,45 & 0,00 & SEM \\
$50 \%$ CZP & 10,91 & 30,64 & 29,22 & 29,22 & SEM \\
$100 \%$ CZP & 10,91 & 30,64 & 0,00 & 58,45 & SEM \\
$0 \%$ CZP+IA & 10,91 & 30,64 & 58,45 & 0,00 & COM \\
50\%CZP+IA & 10,91 & 30,64 & 29,22 & 29,22 & COM \\
100\%CZP+IA & 10,91 & 30,64 & 0,00 & 58,45 & COM \\
\hline
\end{tabular}

Para cada uma das formulações foram moldados corpos-de-prova de argamassa em molde cilíndricos de dimensão $5 \mathrm{~cm}$ (diâmetro) x10 cm (altura) e prismáticos de 4x4x16 cm preenchidos em três e duas camadas respectivamente, sendo que cada camada foi submetida a quinze quedas na mesa de adensamento por queda livre.

Durante 24 horas os corpos-de-prova foram mantidos em seus moldes. Após esse período foi feita a desmoldagem e os corpos-de-prova foram envolvidos por filme plástico seguido de papel alumínio para 
impedir a ocorrência trocas gasosas e líquidas com o meio externo. As amostras foram assim mantidas até a idade de 28 dias em câmara climatizada, sob temperatura e umidade relativa controlada de $23 \pm 1^{\circ} \mathrm{C}$ e $55 \pm 5 \%$, respectivamente.

Ao completarem-se 28 dias de idade de cura as amostras foram secas em estufa ventilada a $50^{\circ} \mathrm{C}$ e monitoradas até ser atingida a constância de massa. Esta temperatura foi utilizada para evitar a degradação térmica das fases hidratadas da argamassa à base de cimento Portland, uma vez que a desidratação da gipsita começa em torno de $80^{\circ} \mathrm{C}$ e que a decomposição da etringita ocorre a cerca de $60^{\circ} \mathrm{C}$ [ 1드.

Todas as análises foram realizadas nas amostras com idade de 28 dias e a absorção capilar foi também determinada nas amostras com 120 dias de idade. As propriedades avaliadas nas argamassas e os ensaios realizados estão relacionadas abaixo:

- massa específica, segundo NBR13280/95 [16] com modificações;

- porosidade aberta [17];

- secagem;

- absorção de água por capilaridade [18] e secagem;

- isoterma de adsorção, segundo ASTM C 1498 [19];

- ângulo de molhamento aparente.

As modificações efetuadas na determinação da massa específica em relação ao proposto pela NBR13280/95 dizem respeito à dimensão da amostra e à determinação do volume da amostra que foi medido por meio de imersão em mercúrio.

Para determinação da porosidade aberta, que é definida como a razão entre o volume dos poros acessíveis às moléculas de água e o volume total da amostra, foram medidas a massa seca, a massa saturada em água com superfície seca e a massa imersa em água da amostra saturada.

No ensaio para determinação da absorção de água por capilaridade foi empregado um tubo de Mariotte graduado (pressão hidráulica nula) para monitoramento da absorção capilar ao longo do tempo até constância do volume absorvido [20]. Na absorção capilar empregou-se água destilada e deionizada. Para determinação do ângulo de molhamento aparente foi utilizado o mesmo aparato do ensaio de absorção de água por capilaridade. A única modificação consistiu na substituição da água destilada e deionizada por álcool etílico (padrão analítico PA). As amostras ensaiadas foram as mesmas utilizadas no ensaio de absorção capilar com água. Em ambos os ensaios, as amostras encontravam-se inicialmente secas. O aparato utilizado está ilustrado na Figura 4.

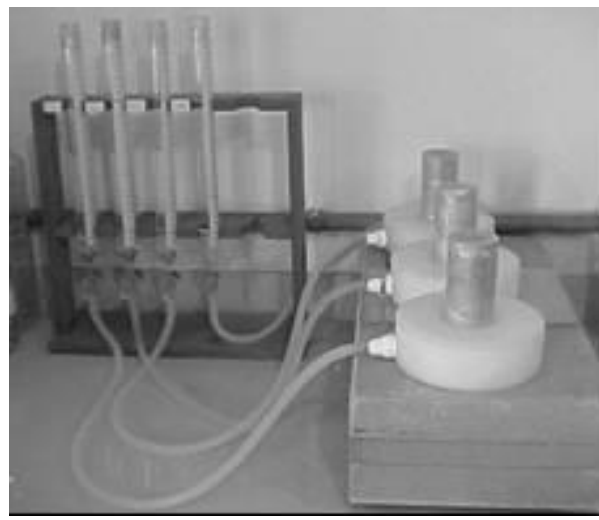

Figura 4: Aparato experimental do ensaio de absorção de água por capilaridade

Para o ensaio de secagem ao ar as amostras, previamente saturadas por imersão em água fria por 72 horas, foram secas em condições controladas de temperatura e umidade relativa $\left(\mathrm{T}=25 \pm 3^{\circ} \mathrm{C}\right.$ e $\left.\mathrm{UR}=60 \pm 5 \%\right)$. Nessas faixas de umidade relativa e temperatura apenas a água capilar e adsorvida presentes na mistura são retiradas.

O ensaio para determinação das isotermas de adsorção consistiu basicamente em colocar uma amostra em uma atmosfera em equilíbrio com solução salina saturada com corpo de fundo, cuja função era manter a umidade relativa constante. A medida realizada consiste na determinação da quantidade de água adsorvida para diferentes valores de umidade relativa no estado de equilíbrio, sendo que esta é obtida através de método gravimétrico. 
Nesse ensaio, foram empregados sete sais diferentes: hidróxido de potássio, acetato de potássio, cloreto de magnésio, bicromato de sódio, nitrito de sódio, cloreto de sódio e sulfato de potássio. Tais sais na temperatura de $50^{\circ} \mathrm{C}$ forneceram os seguintes valores de umidade relativa de equilíbrio: 6, 20, 31, 47, 65, 76 e $96 \%$ respectivamente.

\section{RESULTADOS E DISCUSSÃO}

Para melhor análise dos resultados, determinaram-se estatisticamente, através de análise de variância dos resultados, os parâmetros que influem significativamente, com $95 \%$ de confiabilidade, nas propriedades avaliadas das argamassas.

\subsection{Propriedades Físicas das Argamassas}

Para a massa específica aparente no estado endurecido os parâmetros que influem significativamente são o teor de cinza pesada CZP, o IA, bem como a inter-relação entre estes. No entanto, o parâmetros mais significativo é o incorporador de ar, seguido da CZP, que possui praticamente a mesma influência. Ambos provocam a redução da massa específica, o que está de acordo com o fato da massa específica da CZP ser cerca de $30 \%$ menor do que a da areia e com a ação do incorporador de ar na promoção do aumento do teor de ar incorporado. Essas constatações podem ser feitas através da Figura 5. Pode-se observar que a massa específica varia linearmente com o teor de CZP.

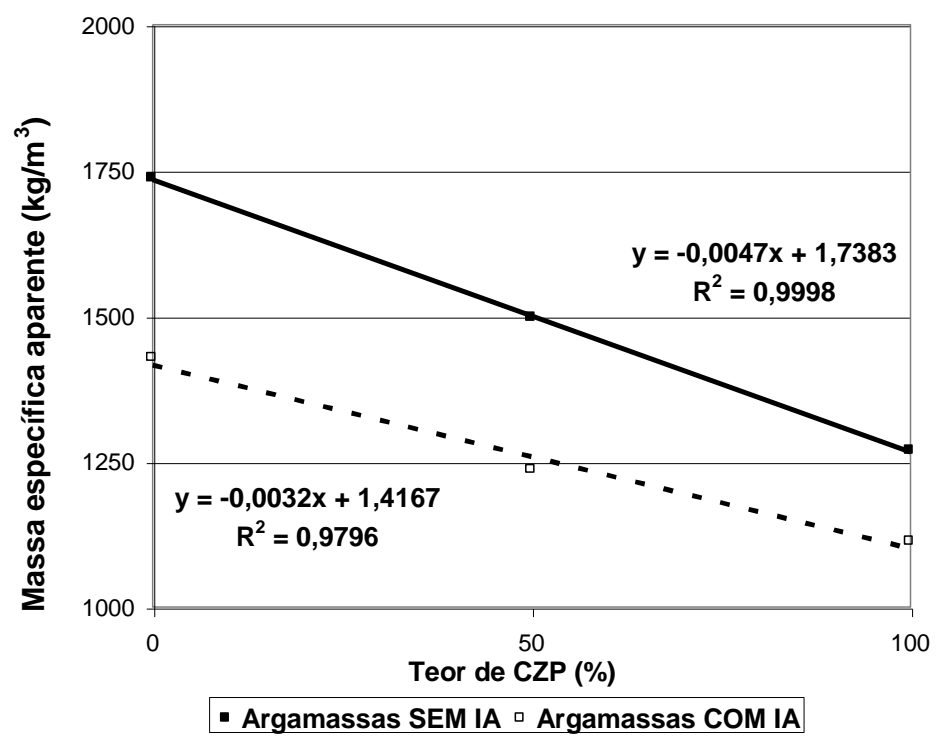

Figura 5: Massa específica aparente das argamassas

O teor de cinza, o incorporador de ar e a inter-relação entre estes parâmetros influem significativamente na porosidade aberta das argamassas. A cinza pesada promove o aumento da porosidade, enquanto o aditivo, a sua redução. Dentre esses parâmetros, a cinza pesada tem maior influência, sendo que a porosidade aberta varia linearmente com o teor de CZP, conforme pode ser observado por meio da Figura 6. 


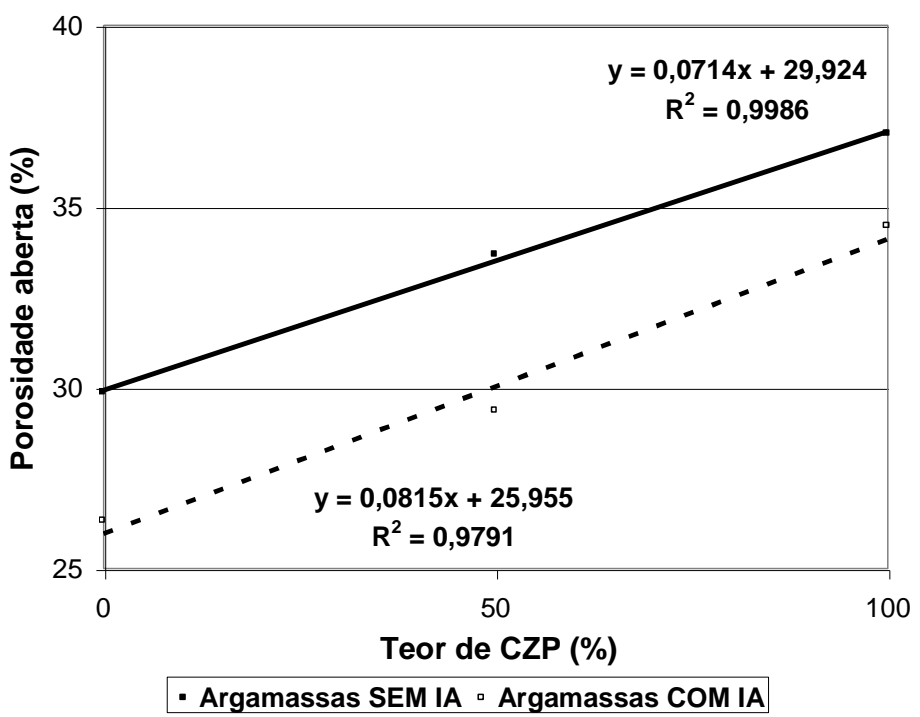

Figura 6: Porosidade aberta das argamassas

\subsection{Secagem da Água de Cura}

O teor de cinza e o emprego do aditivo influem significativamente no volume de água perdido durante a secagem da água de cura. O efeito das duas variáveis é contrário um em relação ao outro, já que a cinza promove o aumento e o incorporador de ar a redução do volume de água perdida na secagem. Dentre eles o que mais influi é o incorporador de ar. Estas observações podem ser realizadas através da Figura 7.

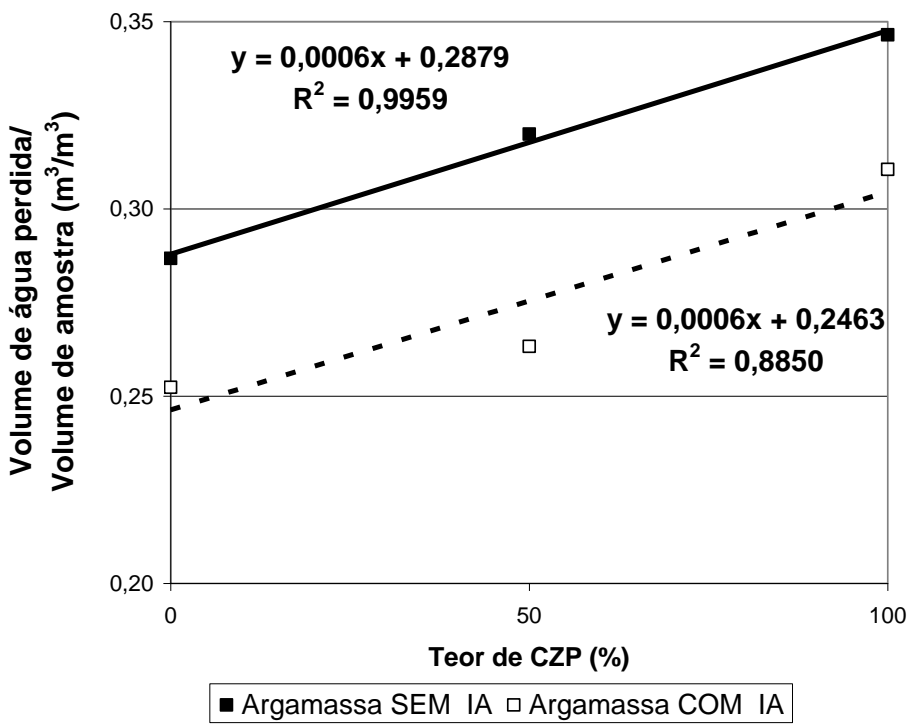

Figura 7: Volume de água perdida durante a secagem da água de cura

\subsection{Absorção de Água por Capilaridade}

Na Figura 8, está apresentada a relação entre o volume de líquido absorvido por área da seção transversal do corpo-de-prova em função da raiz quadrada do tempo $(\sqrt{ } \mathrm{t})$. Por meio dessa relação, que é linear para tempos iniciais (da ordem de horas) [20], [21], foi obtido o coeficiente de sorptividade (s) por intermédio da Equação (6). 


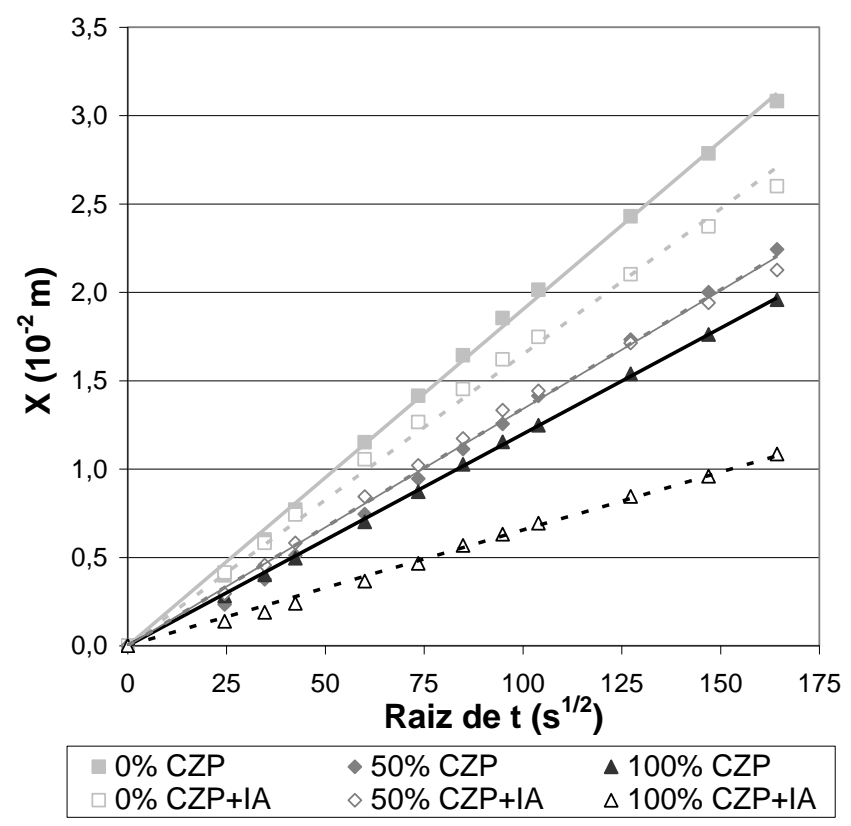

$$
\begin{aligned}
& \hline 0 \% \text { CZP } \\
& \hline y=0,0190 x \\
& R^{2}=0,9984 \\
& 0 \% \text { CZP+IA } \\
& y=0,0165 x \\
& R^{2}=0,9957 \\
& 50 \% \text { CZP } \\
& y=0,0134 x \\
& R^{2}=0,9947 \\
& 50 \% \text { CZP+IA } \\
& y=0,0134 x \\
& R^{2}=0,9963 \\
& 100 \% \text { CZP } \\
& y=0,0120 x \\
& R^{2}=0,9996 \\
& 100 \% C Z P+I A \\
& \hline y=0,0065 x \\
& R^{2}=0,9962
\end{aligned}
$$

Figura 8: Volume de líquido absorvido por área da seção transversal $(X)$ em função de $\sqrt{t}_{t}$

Para as argamassas estudadas, o coeficiente de sorptividade é influenciado significativamente pelo teor de CZP, o emprego de IA e a inter-relação entre estes parâmetros, sendo que todos eles promovem a redução da sorptividade. Porém, a redução promovida pela cinza pesada é mais significativa e pode ocorrer em função do refinamento dos poros das argamassas. Tal refinamento pode ser causado pela CZP, por causa da sua finura (efeito filler) e em virtude do seu potencial pozolânico [22].

O incorporador de ar parece estar atuando na redução dos capilares acessíveis à água e/ou tornando mais heterogêneo o circuito dos raios dos poros.

O coeficiente de sorptividade em função da idade está apresentado na Figura 9. A idade é o parâmetro que mais influencia na sorptividade. A redução na sorptividade em função da idade evidencia que ocorre uma modificação importante na distribuição do tamanho de poros ao longo dos 28 dias até cerca de 120 dias de idade. Tal redução é mais significativa nas argamassas com as cinzas pesadas, em virtude da reação pozolânica [11].

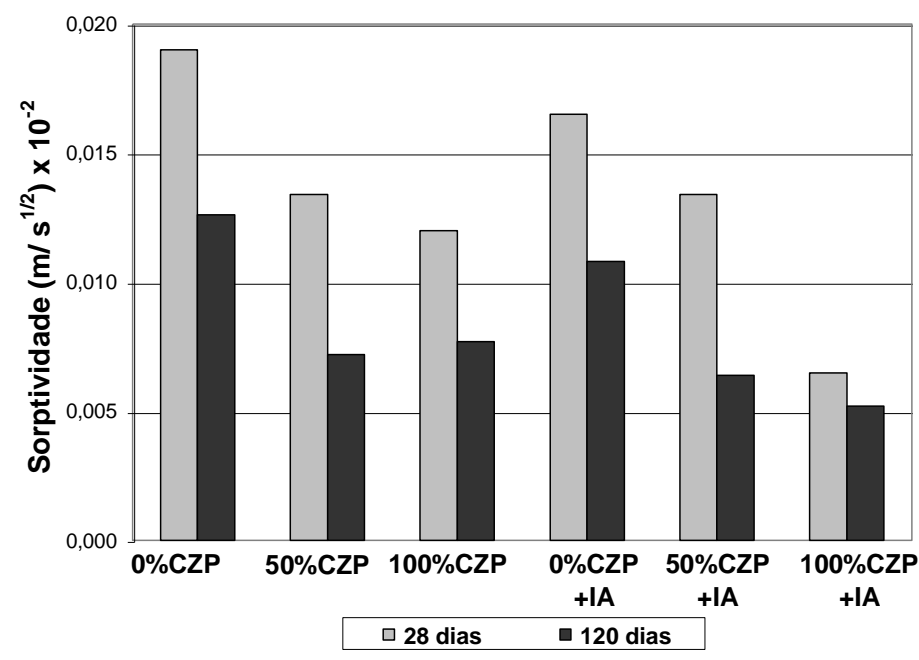

Figura 9: Coeficiente de sorptividade em função da idade 


\subsection{Secagem ao Ar}

Por meio da Figura 10 é possível observar que as argamassas com cinzas, apesar de possuírem maior conteúdo de umidade inicial, apresentaram menor fluxo de secagem e maior conteúdo de umidade residual. Isso sugere que as argamassas produzidas com as cinzas apresentam maior distribuição de poros mais finos. Tal efeito foi igualemente encontrado nas análises de Barbare et al [12].

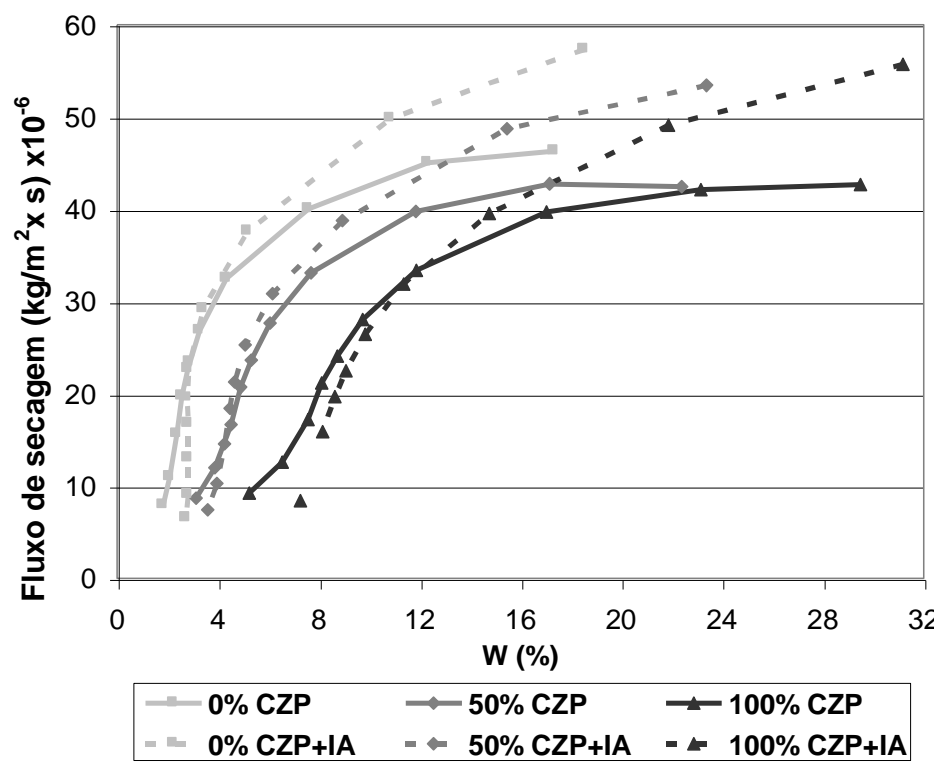

Figura 10: Fluxo de secagem em função do conteúdo de umidade mássico (W)

\subsection{Adsorção}

Os dados experimentais do ensaio de adsorção ajustam-se bem ao modelo GAB em todo o domínio de umidades relativas. Os coeficientes são fornecidos na tabela 4 , com as correlações $\mathrm{R}^{2}$ variando de 0,7854 a 0,9942. No entanto, o modelo foi melhor ajustado para os dados experimentais das argamassas produzidas com as cinzas pesadas com teores de até $50 \%$ de cinzas em substituição à areia natural. Na Figura 11 são apresentadas as isotermas de adsorção obtidas através deste ajuste.

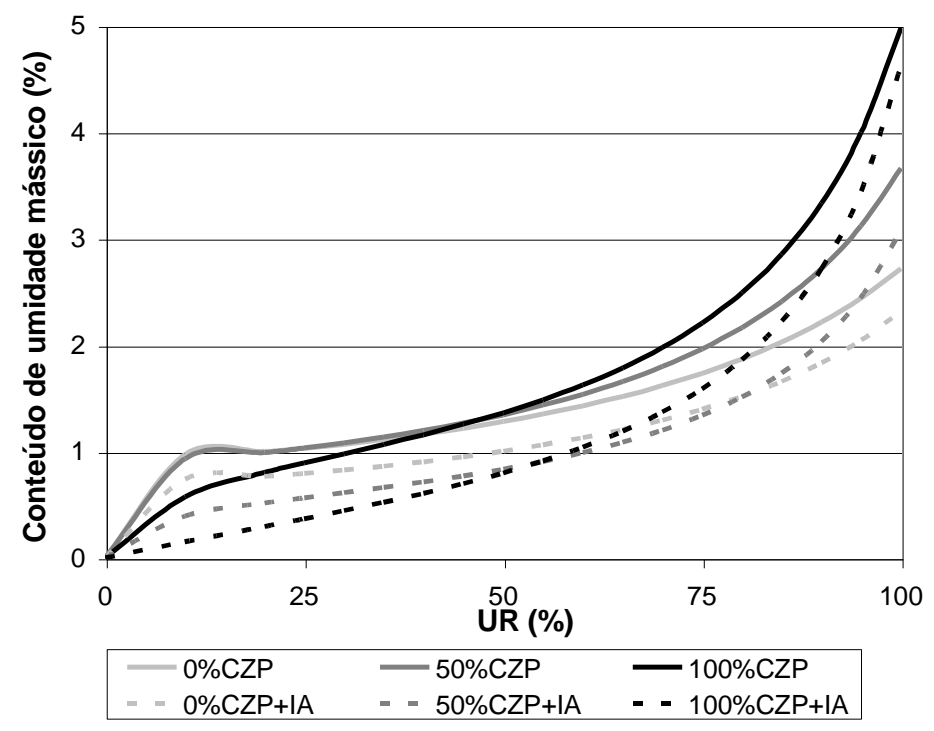

Figura 11: Isotermas de adsorção ajustadas pelo modelo GAB 
Tabela 4: Coeficientes determinados pelo modelo GAB

\begin{tabular}{|l|c|c|c|c|}
\hline \multirow{2}{*}{ Argamassa } & \multicolumn{4}{|c|}{ Coeficientes } \\
\cline { 2 - 5 } & $\mathbf{A}$ & $\mathbf{B}$ & $\mathbf{C}$ & $\mathbf{R}^{\mathbf{2}}$ \\
\hline $\mathbf{0 \% C Z P}$ & $-85,007$ & 122,960 & $-1,123$ & $\mathbf{0 , 9 9 4 2}$ \\
\hline $\mathbf{5 0 \% C Z P}$ & $-95,368$ & 123,320 & $-0,613$ & $\mathbf{0 , 9 7 6 7}$ \\
\hline $\mathbf{1 0 0} \%$ CZP & $-90,304$ & 102,250 & 8,148 & $\mathbf{0 , 8 8 2 4}$ \\
\hline $\mathbf{0 \% C Z P + I A}$ & $-116,100$ & 160,680 & $-1,377$ & $\mathbf{0 , 9 4 2 0}$ \\
\hline $\mathbf{5 0 \% C Z P + I A}$ & $-156,740$ & 180,110 & 9,194 & $\mathbf{0 , 9 8 4 2}$ \\
\hline $\mathbf{1 0 0} \% \mathbf{C Z P + I A}$ & $\mathbf{- 8 0 , 9 5 0}$ & $\mathbf{3 9 , 1 0 3}$ & $\mathbf{6 3 , 5 1 3}$ & $\mathbf{0 , 7 8 5 4}$ \\
\hline
\end{tabular}

As argamassas, ao serem submetidas a valores crescentes de umidade relativa, fixam a umidade por adsorção. Através da Figura 13, é possível constatar que, quanto maior o teor de cinza pesada, maior é a quantidade de água adsorvida nas paredes dos poros das argamassas para teores de umidade relativa (UR) elevados (96\%). Esse aumento pode ser decorrente de um volume maior de microporos (raio inferior a $20 \mathrm{~A}$ ) e mesoporos (raio entre 20 e 500 A). Para o o material com macroporos (raio superior a 500 A) a adsorção desempenha um papel pouco significativo e a condensação capilar começa apenas para valores de umidade relativa muito próximos de $100 \%$.

A condensação capilar, de acordo com a Lei de Kelvin-Laplace, ocorre somente nos poros de raio menor que o raio crítico, sendo que este é função da umidade relativa. Os valores do raio crítico para a temperatura de $50^{\circ} \mathrm{C}$ e para os valores de umidade relativa abordados no ensaio das isotermas foram calculados a partir da Eq. (2) e estão apresentados na Tabela 5.

Tabela 5: Raio crítico em função da umidade relativa $\left(\mathrm{T}=50^{\circ} \mathrm{C}\right)$

\begin{tabular}{|l|l|l|l|l|l|l|l|}
\hline UR $(\%)$ & 6 & 20 & 31 & 47 & 65 & 76 & 96 \\
\hline Raio crítico $\left(\mathrm{A}^{\mathrm{o}}\right)$ & 4 & 6 & 9 & 13 & 23 & 37 & 246 \\
\hline
\end{tabular}

Os dados da Tabela 5 indicam que, para valores de UR até cerca de $60 \%$, a condensação capilar apenas ocorre nos microporos; para valores de UR entre 60\% e 96\% esta ocorre nos mesoporos das argamassas estudadas.

Analisando-se o efeito do IA verifica-se que este promoveu a redução da quantidade de água adsorvida, sendo que a forma da curva permaneceu praticamente inalterada.

Em síntese, as diferenças existentes nas isotermas das argamassas revelam diferenças na distribuição de tamanhos de poros e na quantidade destes.

Através do ensaio de adsorção também foi possível determinar a superfície específica (Equação 1). Os resultados são apresentados na Figura 12. Para uma mesma porosidade um meio com uma superfície específica elevada será dividido mais finamente que um meio de uperfície específica baixa. É possível verificar que o parâmetro que governa a superfície específica é o aditivo incorporador de ar. Portanto, o efeito desse aditivo é de reduzir a superfície específica. 


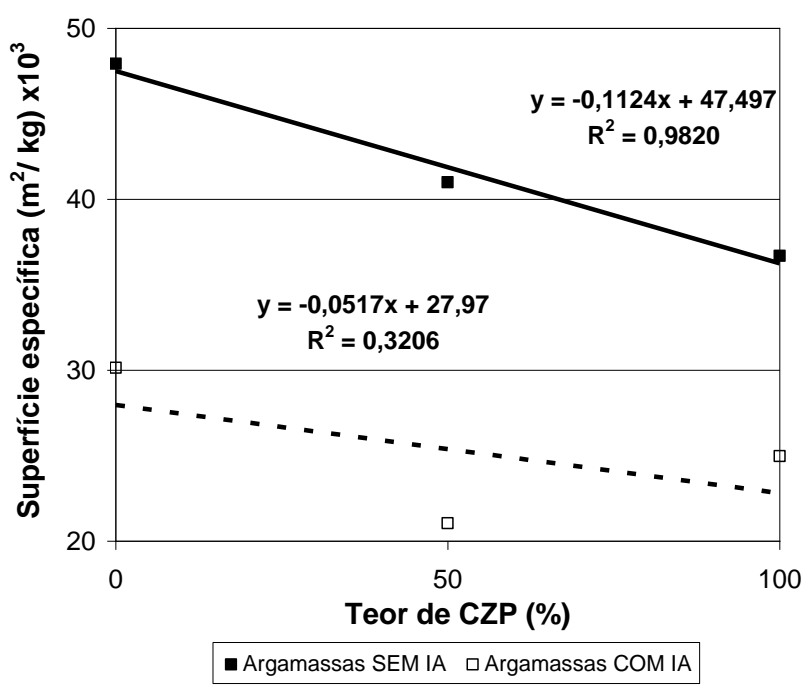

Figura 12: Superfície específica das argamassas

\section{6 Ângulo de Molhamento Aparente}

Na Figura 13 é apresentado o ângulo de molhamento aparente em função do teor de CZP, que foi determinado por meio das Equações (4) e (5).

Há uma tendência da cinza pesada CZP e do aditivo em promoverem a redução da molhabilidade (aumento do ângulo de molhabilidade). Esta redução deve-se à ação das cinzas pesadas nas argamassas, pois, no ensaio de absorção de água, tais argamassas apresentam maior tempo de ascensão da franja capilar e menor sorptividade. O aditivo incorporador promove a formação de poros isolados não interconectados reduzindo a molhabilidade do material.

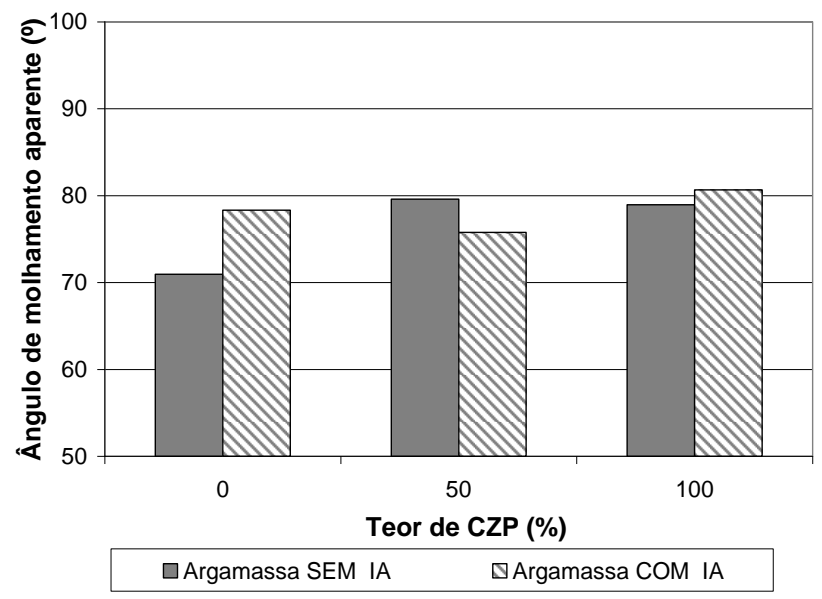

Figura 13: Ângulo de molhamento aparente em função do teor de CZP

\section{CONCLUSÕES}

Uma das maiores potencialidades do uso das cinzas pesadas está no emprego como agregado em materiais à base de cimento Portland. A natureza porosa, sua pozolanicidade, a baixa densidade, aliadas à grande disponibilidade são indicativos de um material potencial para emprego como agregados.

O procedimento experimental utilizado foi capaz de evidenciar a variabilidade das propriedades higrotérmicas das argamassas em função dos parâmetros teor de cinza pesada e emprego de aditivo incorporador de ar, bem como determinar quais destes parâmetros influem significativamente em cada propriedade e os seus efeitos. Na aplicação avaliada, tanto o teor de cinza pesada quanto o emprego de 
aditivo incorporador de ar são parâmetros que influem significativamente nas propriedades higrotérmicas das argamassas.

Dentre estes dois parâmetros torna-se difícil precisar qual tem maior influência. Já a inter-relação destes dois parâmetros foi comprovada estatisticamente, com 95\% de confiabilidade, no caso das seguintes propriedades: massa específica no estado endurecido, porosidade aberta, volume de água absorvida por capilaridade e sorptividade.

O uso da cinza pesada com o incorporador de ar, mostrou-se bastante interessante já que em muitas das propriedades relacionadas com a transferência de umidade, como na absorção de água por capilaridade e na adsorção de água para umidades relativas elevadas, a cinza pesada provoca um aumento indesejado do conteúdo de umidade fixado, que é compensado pelo emprego do aditivo. Apesar das argamassas com incorporador de ar apresentarem maior quantidade de ar incorporado (vazios) essas apresentaram uma menor porosidade aberta. Logo, grande parte destes vazios não é permeável a água, ou seja, encontram-se na forma de poros não interligados. Em função da redução da porosidade aberta promovida pelo incorporador de ar as argamassas tornam-se menos suscetíveis à penetração da água de chuva, demonstrado pelo melhor desempenho hídrico nas propriedades avaliadas.

\section{BIBLIOGRAFIA}

[1] BAROGHEL, B.V., MAINGUY, M., LASSABATERE, T., COUSSY, O., "Characterization and Identification of Equilibrium and Transfer Moisture Properties for Ordinary and high-performance Cementitious Materials", Cement and Concrete Research, v. 29, n. 8, pp. 1225-1238, August 1999.

[2] KOOI, V. D., Moisture transport in cellular concrete roofs, Ph.D. Thesis, University of Tecnology, Waltman Delft, Netherlands, 1971.

[3] PERRIN, B., "Etude des Transferts Couples de Chaleur et de Masse dans des Materiaux Poreux Consolides non Satures Utilises en Genie Civil", These Docteur, Universite Paul Sabatier de Toulose, Tolouse, France, 1985.

[4] MEROUANI, L., "Phénomènes de Sorption et de Transfert d'Humidité dans des Matériaux du Bâtiment. Étude Expérimentale Comparative dún Mortier de Ciment et d'un Enduit de Façade", Thèse Docteur, 3 Cycle, Institut National Polytechnique de Grenoble, France, 1987.

[5] FREITAS, V.P., ABRANTES, V., CRAUSSE, P., "Moisture Migration in Building Walls-Analysis of the Interface Phenomena", Building and Environment, v. 31, n. 2, pp. 99-108, March 1996.

[6] MENDES, N., "Modelos para Previsão da Transferência de Calor e de Umidade em Elementos Porosos de Edificações”, Tese de D.Sc, UFSC, Florianópolis, SC, Brasil, 1997.

[7] KUMARAN, K., LACKEY, J., NORMANDIN, N., VAN REENEN, D., TARIKU, F., "Heat, Air and Moisture Transport Properties of Several North American Bricks and Mortar Mixes", Journal of Testing and Evaluation, v. 32, n. 5, pp. 383-389, 2004.

[8] CSTC, “Comportement à L'humidité des Eléments de Construction, Application aux Toitures”, CSTC, n. 1, Bruxelles, 1982.

[9] HALL, C., "Barrier Performance of Concrete: A Review of Fluid Transport Theory", Materials and Structures, n. 27, pp. 291-306, 1994.

[10] CHERIAF, M., ROCHA, J.C., PERA, J., POZZOBON, C.E., "Reciclagem e Utilização dos Resíduos do Carvão", In: Meio Ambiente e Carvão: Impactos da exploração e utilização, FINEP, CAPES, PADCT/GTM, PUCRS, UFSC, FEPAM. (org.), pp. 373-409, v. 1, Porto Alegre, 2002.

[11] CHERIAF, M., PÉRA, J., ROCHA, J.C., "Pozzolanic Properties of Pulverized Coal Combustion Bottom Ash", Cement and Concrete Research, v. 29., n. 9, pp. 1387-1391, 1999.

[12] BARBARE, N., SHUKLA, A., BOSE, A., "Uptake and Loss of Water in a Cenosphere-Concrete Composite Material”, Cement and Concrete Research, v. 33, n. 10, pp. 1681-1686, October 2003. 
[13] ASTM C 618, Standard Specification for Coal fly ash and raw of Calcined Natural Pozzolan for use as a Mineral Admixture in Portland Cement Concrete, 1995.

[14] ASSOCIAÇÃO BRASILEIRA DE NORMAS TÉCNICAS, "Materiais Pozolânicos - Determinação de Atividade Pozolânica com cimento Portland - Indice de Atividade Pozolânica com Cimento", NBR 5752, Rio de Janeiro, 1992.

[15] GALLÉ, C., "Effect of Drying on cement-based Materials pore Structure as Identified by Mercury Intrusion Porosimetry: A Comparative Study Between oven-, vacuum-, and freeze-drying", Cement and Concrete Research, v. 31, n. 10, pp. 1467-1477, October 2001.

[16] ASSOCIAÇÃO BRASILEIRA DE NORMAS TÉCNICAS, Argamassa de Assentamento de Paredes e Revestimento de Paredes e tetos - Determinação da Densidade de Massa Aparente no Estado Endurecido, NBR13280, Rio de Janeiro, 1995.

[17] SAFIUDDIN, M.D., HEARN, N. "Comparison of ASTM Saturation Techniques for Measuring the Permeable Porosity of Concrete", Cement and Concrete Research, v. 35, n. 5, pp. 1008-1013, May 2005.

[18] ASSOCIAÇÃO BRASILEIRA DE NORMAS TÉCNICAS, Argamassa e Concreto Endurecidos Determinação da Absorção de Água por Imersão - Índice de Vazios e Massa Específica, NBR 9778, Rio de Janeiro, 1987.

[19] ASTM C 1498, Standard Test Method for Hygroscopic Sorption Isotherms of Building Materials, 2001.

[20] SANTOS, F.I.G., LENZI, E.J., ROCHA, J.C., CHERIAF, M., “Avaliação de Resíduos para uso em Argamassas - Estudo com Cinza Pesada”, In: I Conferência Latino-Americana de Construção Sustentável/ ENTAC04 - 10 Encontro Nacional de Tecnologia do Ambiente Construído, São Paulo, Julho 2004.

[21] MARTYS, N.S., FERRARIS, C.F., "Capillary transport in mortars and concrete", Cement and Concrete Research, v. 27, n. 5, pp. 747-760, May 1997.

[22] ANDRADE, L.B., ROCHA, J.C., CHERIAF, M. "Evaluation of Concrete Incorporating Bottom ash as Natural Aggregates Replacement". Waste Management (Elmsford), v. 27, n. 9, pp. 1190-1199, 2007. 